http://jmscr.igmpublication.org/home/

ISSN (e)-2347-176x ISSN (p) 2455-0450

crossref DOI: https://dx.doi.org/10.18535/jmscr/v7i12.76

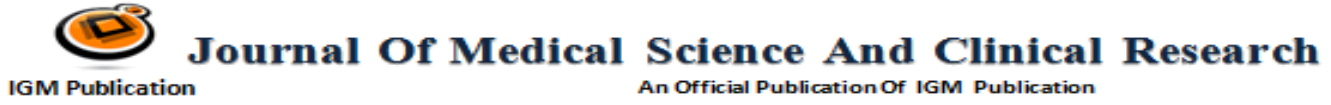

\title{
A Clinico-Epidemiological and Mycological Study of Dermatophytosis in a Tertiary Care Centre in Odisha
}

\author{
Authors \\ Karimnagar, Telangana \\ *Corresponding Author \\ Venkatesh Mandava
}

Venkatesh Mandava ${ }^{1 *}$, Nishita Vumma ${ }^{2}$

${ }^{1}$ Post Graduate, Department of Dermatology, Kalinga Institute of Medical Sciences, Bhubaneshwar, Odisha

${ }^{2}$ Post Graduate, Department Of Dermatology, Chalmeda Anand Rao Institute of Medical Sciences,

\begin{abstract}
Introduction: Dermatophytosis is a disease condition characterized by the infection of keratinized tissues such as epidermis, hair and nails. This condition is caused by a group of closely related filamentous fungi commonly known as Dermatophytes. Epidermophyton, Microsporum and Trichophyton are the genera of dermatophytes implicated in superficial mycoses.

Aims and Objectives: The present study has been taken to assess the epidemiological profile and the fungal species causing Dermatophytosis and to assess the clinical diagnosis with KOH smear positivity and culture positivity.

Methods: In a total of 380 clinically diagnosed cases of Dermatophytosis, specimens (scales, hair, nail clippings) were collected. This material was subjected to Direct Microscopy with $\mathrm{KOH}$ and culture test.

Results: Tinea corporis was the most common clinical type (46.1\%) followed by Tinea cruris (25.5\%). Most of the patients were in the age group of 21-30 years (37.4\%) followed by 31-40 years and males were commonly affected than females with a ratio of 1.79:1. Majority of patients were Active workers by occupation (40\%) belonging to lower socioeconomic status (73.4\%). Overall positivity by culture was $60.5 \%$ and by Direct Microscopy $(\mathrm{KOH})$ was $71.6 \%$. Trichophyton mentagrophyte was the predominant species isolated (36.3\%) followed by Trichophyton rubrum (18.2\%).

Conclusion: Dermatophytosis are infections seen commonly in people who work in hot and humid conditions and those who indulge in strenous work. Clothing patterns and personal hygiene also play an important role. By taking proper precautionary measures the incidence and disease burden can be minimized.
\end{abstract}

\section{Introduction}

Dermatophytosis is a disease condition infecting the keratinized tissues such as the epidermis, nails, and hairs. It is caused by a group of filamentous fungi known as Dermatophytes. ${ }^{1,2,3}$ Epidermophyton, Microsporum and Trichophyton are the three genera of fungi involved in cutaneous mycoses. 4
Dermatophytosis are the most common of the superficial fungal infections. It is common in tropics and subtropics. Socioeconomic factors like overcrowding, poor hygiene and malnutrition together with individual susceptibility play an important role. ${ }^{5}$ Although dermatophytosis does not cause mortality, it does cause morbidity and poses a major public health problem especially in 
tropical countries like India due to the hot and humid climate. ${ }^{6}$

The distribution and frequency of dermatophytosis and their etiologic agents vary according to the geographic region, the socioeconomic level, the climatic variations, the presence of domestic animals, and age. ${ }^{7}$

There seems to be a change in the trend of the causative organism of dermatophytosis of glabrous skin. Trichophyton rubrum which is the most common agent of tinea infection of the body has become less prevalent compared to the yester years while Trichophyton mentagrophytes has emerged as codominant or predominant pathogen. In this context, this study has been undertaken to assess the clinical profile of dermatophytic infections and to identify the causative fungal species in the various clinical presentations.

\section{Aims \& Objectives}

1. To study the clinical types of Dermatophytosis.

2. To find out the relation of Dermatophytosis to age, sex, occupation and socioeconomic status.

3. Isolation and identification of Dermatophytes.

4. Correlation between the site of involvement and the causative agent.

\section{Material and Methods}

Study Design: A descriptive Cross-sectional study

Study Site: Outpatient department of Skin \& Venerology Department, Kalinga Institute of Medical Sciences, Bhubaneswar.

Study Period: September 2017 to September 2019.

Study Population: Clinically diagnosed cases of dermatophytosis attending Outpatient department of Skin \& Venerology Department during the study period.

Sample Size: By adopting $45 \%$ of prevalence at $5 \%$ of absolute precision with $95 \%$ of desired confidence level, the required subjects obtained were 380 .

$$
\begin{aligned}
& \mathrm{N}=\mathrm{Z}^{2} \mathrm{PQ} / \mathrm{L}^{2} \mathrm{Z}=1.96 \\
& \mathrm{P}=45 \% \\
& \mathrm{Q}=100-\mathrm{P}=100-45=55 \% \mathrm{~L}=5 \% \\
& \mathrm{~N}=1.96 * 1.96 * 45 * 55 / 5 * 5 \\
& =9507.96 / 25 \\
& =380.3
\end{aligned}
$$

\section{Inclusion Criteria}

Patients of all ages and of both the sexes who are clinically suspected with dermatophytic infection of skin, hair or nails and who are not using any antifungal treatment for minimum of one week.

$\square$ Patients who gave informed consent for required investigations.

\section{Exclusion Criteria}

Patients treated with antifungals or topical steroids in the recent past.

$\square$ Patients with those superficial fungal infections which are not caused by dermatophytes, such as Pityriasis versicolor and Candidiasis.

$\square$ Patients with secondary bacterial infection.

$\square$ Patients with subcutaneous and deep fungal infection.

$\square$ Patients with Immunodeficiency, Diabetes and other chronic diseases etc.

\section{Method of Collection of Data}

Proforma was designed for each patient. Data was collected, tabulated and statistical analysis was done. The affected area was cleaned with $70 \%$ ethyl alcohol and depending on the presenting condition skin scales, crusts, were collected from active outer border with BP blade no. 15 and put on a glass slide. Nail specimen was collected by taking clippings of the with a nail clipper. Hair specimen was collected by plucking hair with epilating forceps along with the root end.

\section{Direct Microscopic Examination}

Specimen collected on a glass slide. A few drops of $\mathrm{KOH}$ were added and a cover slip placed on it (10\% for skin and hair; $40 \%$ for nail) to 
disintegrate keratin. It was then left for 15-20 minutes in case of skin scrapings and overnight for nails. Specimen examined under the low power of microscope, then high power for hyphae-highly refractile, hyaline, septate branching filaments.

\section{Culture}

Sabouraud's dextrose agar, SDA with $0.05 \%$ chloramphenicol and $0.5 \%$ cycloheximide and dermatophyte test medium ( 3 test tubes).The first two test tubes are incubated at $280 \mathrm{C}$ for $2-4$ weeks and was observed periodically for growth. If no growth was found after 4 weeks, its negative. The third test tube will be incubated at $280 \mathrm{C}$ for up to ten days and observed for colour change. Fungal isolates were identified based on colony morphology, pigmentation, growth rate and microscopy (LPCB mount)

\section{Results}

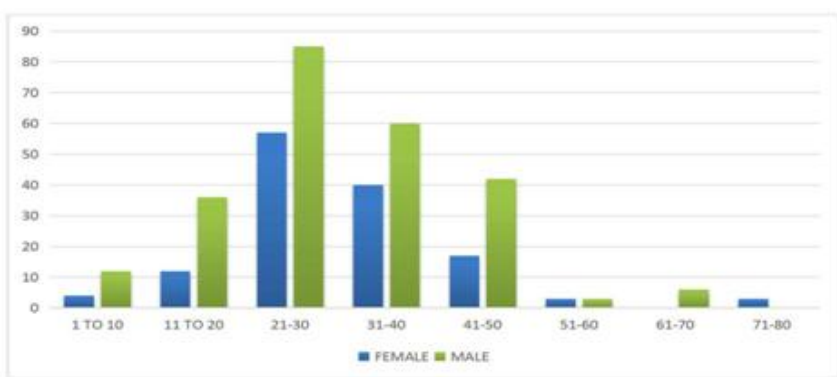

Graph 1: Age distribution of cases

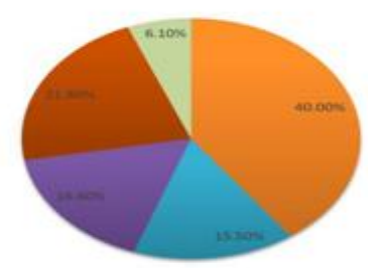

Graph 2: Distribution of study participants on occupation

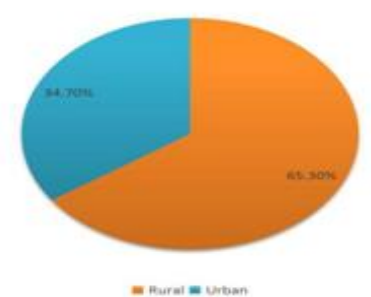

Graph 3: Distribution of study participants on residence

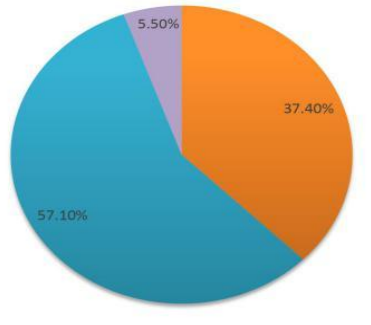

= Rainy $\mathbf{w}$ Summer $\mathbf{m}$ Winter

Graph 4: Seasonal incidence of dermatophytosis

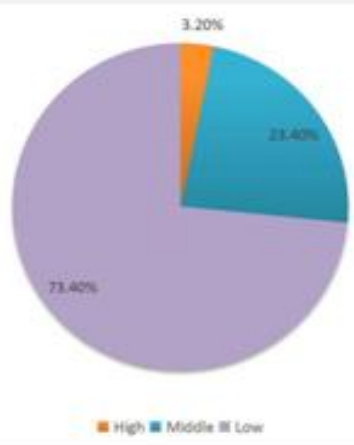

Graph 5: Distribution of socioeconomic status

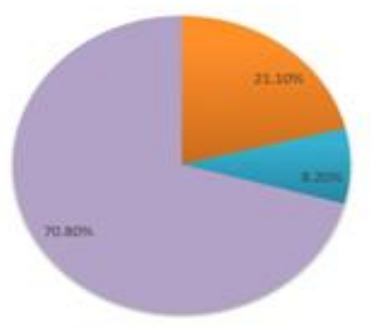

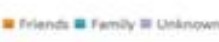

Graph 6: Source of infection

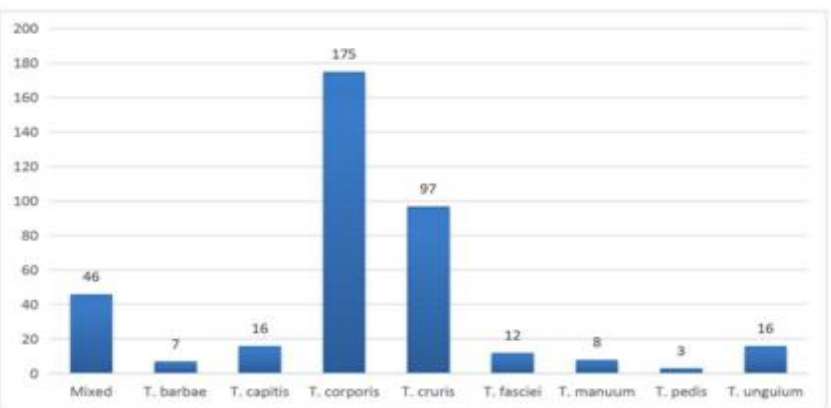

Graph 7: Distribution of study participants based on clinical type of dermatophytosis

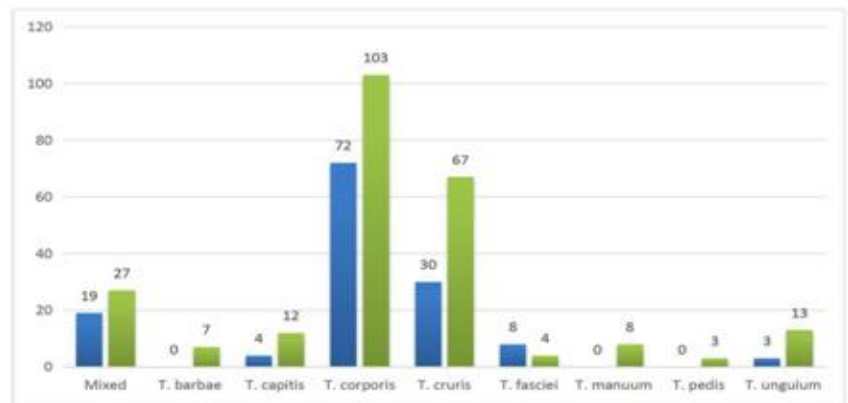

Graph 8: Gender distribution of clinical types 


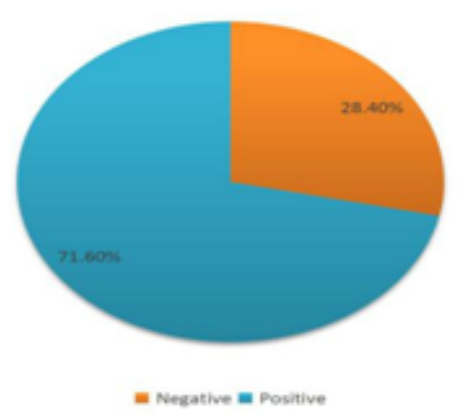

Graph 9: KOH Examination Results

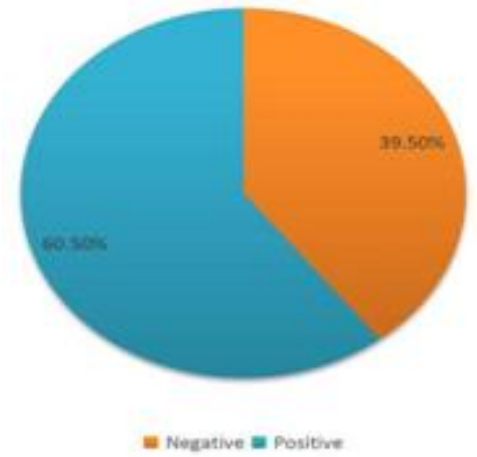

Graph 10: Culture Results

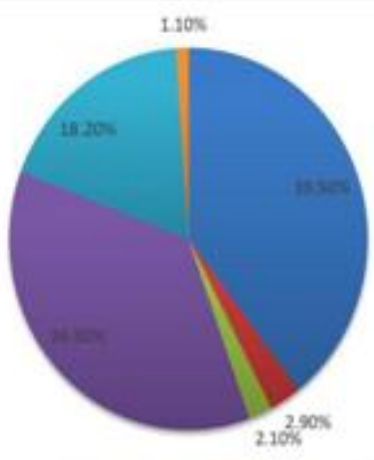

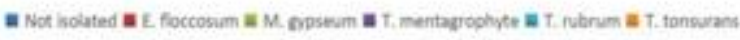

Graph 11: Incidence of Dermatophyte

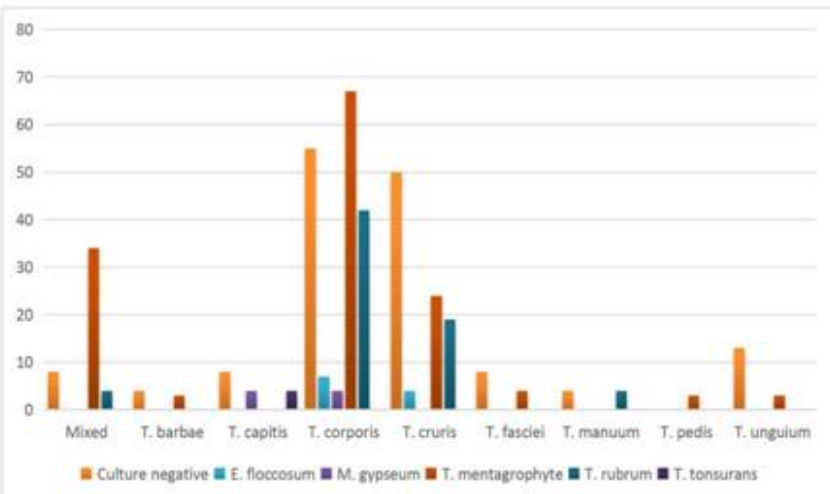

Graph 12: Dermatophytes isolated from various clinical types
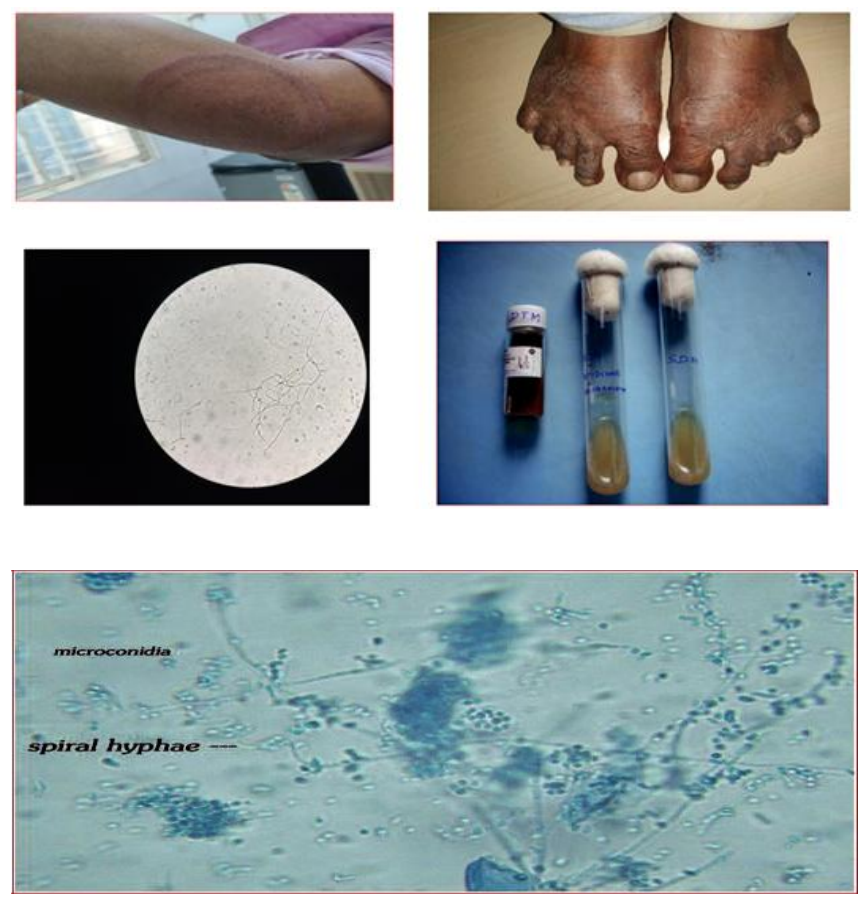

\section{Discussion}

In the present study dermatophytosis was more common in the age group of 21-30 years (37.4\%). The increased incidence of dermatophytosis in this age group is due to the fact that this population group is highly active and mobile and takes part in maximum outdoor activities like agriculture and manual labour, which predisposes them to acquire infection from environmental exposure.

In our study males $(64.2 \%)$ outnumbered females $(35.8 \%)$ and male to female ratio was found to be 1.79:1. The higher incidence in males could be due to greater physical activity and increased sweating.

In the present study, Active workers (farmers, daily wage laborers, coolies, agriculturists) comprised majority of the patients $(40 \%)$ followed by students $(21.8 \%)$, sedentary workers $(16.6 \%)$ and Housewives (15.5\%). Higher incidence of Dermatophytosis in active workers may be due to more physical exertion and exposure to environment leading to more perspiration and thence infection.

Higher incidence of Dermatophytosis (especially T.capitis) in students may be assumed to higher freedom of movement, carelessness and lack of guidance regarding personal hygiene. 
In the present study, majority of the cases $(65.3 \%)$ were from rural areas. The higher incidence of Dermatophytosis in rural areas may be due to poor personal hygiene compared to urban people.

In the present study, majority of the cases $(57.1 \%)$ were reported in summer season followed by rainy season (37.4\%). This may be due to increased heat and perspiration in summer.

In the present study, infection was most common among Low socio-economic status (73.4\%), followed by Middle socio-economic status (23.4\%) and High socio-economic status (3.2\%). The higher incidence of Dermatophytosis in low socio-economic status may be due to poor personal hygiene (practice of sharing clothes, towels, etc), poor nutritional status, overcrowding and lack of proper education about sanitation.

- Balamuruganvelu et $\mathrm{al}^{8}$, Mishra $\mathrm{N}$ et $\mathrm{al}^{9}$, Pathania $S$ et $\mathrm{al}^{10}$, Mahajan $\mathrm{S}$ et $\mathrm{al}^{11}$, Venkatesh VN et $\mathrm{al}^{12}$ reported T.mentagrophyte as the commonest species identified similar to my findings.

- Tinea corporis was the commonest clinical type in the present study, seen in $46.1 \%$ of patients which is comparable with studies by Rao BR et $\mathrm{al}^{13}$, Siddappa K et $\mathrm{al}^{14}$, Bindu V et $\mathrm{al}^{15}$, Kaviarasan PK et $\mathrm{al}^{16}$, Singh $\mathrm{S}$ et $\mathrm{al}^{17}$, Poyyamozhi $\mathrm{JS}^{18}$, Sri Sandhya K et $\mathrm{al}^{19}$, Janardhan $\mathrm{B}^{20}$, Vishalakshi $\mathrm{S}$ Pandit $^{21}$, Mahajan $\mathrm{S}$ et $\mathrm{al}^{11}$, Venkatesh $\mathrm{VN}$ et $\mathrm{al}^{12}$, Ramaraj $\mathrm{V}$ et $\mathrm{al}^{22}$, Lavanya $\mathrm{V}^{23}$, Najotra DK et $\mathrm{al}^{24}$ and Venkatesan $\mathrm{G}$ et $\mathrm{al}^{6}$.

- Belurkar DD et $\mathrm{al}^{25}$ reported a culture positivity of $71 \%$ and $\mathrm{KOH}$ positivity of $68.33 \%$.

- Bindu $\mathrm{V}$ et $\mathrm{al}^{15}$ reported a culture positivity of $45 \%$ and $\mathrm{KOH}$ positivity of $64 \%$.

- Guruprasad KY et $\mathrm{al}^{26}$ reported a $\mathrm{KOH}$ positivity of $69.6 \%$ and culture positivity of $40 \%$. Kumar $\mathrm{U}$ et $\mathrm{al}^{27}$ observed $\mathrm{KOH}$ positivity in $71.8 \%$ samples.

- $85.1 \% \mathrm{KOH}$ positivity was observed by Mishra $\mathrm{N}$ et $\mathrm{al}^{9}$. Gupta $\mathrm{SK}$ et $\mathrm{al}^{28}$ reported $78.8 \% \mathrm{KOH}$ positivity.
- Mahajan $\mathrm{S}$ et al ${ }^{11}$ observed $\mathrm{KOH}$ positivity in $79.6 \%$ and culture positivity in $52.4 \%$. Venkatesh $\mathrm{VN}$ et $\mathrm{al}^{12}$ reported $49.3 \% \mathrm{KOH}$ positivity and $46.98 \%$ culture positivity.

- Thus, the results of $\mathrm{KOH}$ and culture vary from study to study and can be due to multiple factors like non-viability of fungal elements, presence of contaminants, certain technical errors etc.

- T.mentagrophyte was the most common isolate in the present study comprising $36.3 \%$ of total isolates. T.mentagrophytes was the most common isolate from T.corporis and second most common isolate from T.cruris.

\section{Conclusion}

A Clinical and Mycological study was conducted on 380 clinically diagnosed cases of dermatophytosis attending the outpatient department of Skin \& Venerology Department, Kalinga Institute of Medical Sciences, Bhubaneswar from September 2017 to September 2019.

$\square \quad$ In the present study, Tinea corporis(46.1\%) was found to be the commonest clinical type followed by Tinea cruris $(25.5 \%)$.

$\square$ Mixed clinical types were seen in $12.1 \%$ of cases.

Tinea corporis with Tinea cruris was the commonest mixed clinical type (50\%) seen more commonly in the age group of 31-40 years with male predominance. Tinea corporis with Tinea faciei was second common mixed type seen in $(26 \%)$.

$\square$ Majority of cases of Dermatophytosis belonged to the age group of 21-30 years $(37.4 \%)$.

Tinea capitis was common in age 1-10 years

$\square$ Dermatophytosis was more common in males $(64.2 \%)$ than in females $(35.8 \%)$. Male to female ratio was 1.79:1.

Majority of patients were Active workers (40\%). 
Incidence of Dermatophytosis is maximum in rural areas (65.3\%), low socioeconomic group and in summer.

Majority of patients studied were poor $(73.4 \%)$.

$57.1 \%$ were both $\mathrm{KOH}$ and culture positive, $14.5 \%$ were $\mathrm{KOH}$ positive but culture negative, $3.4 \%$ were culture positive but $\mathrm{KOH}$ negative and $25.0 \%$ were both $\mathrm{KOH}$ and culture negative.

Trichophyton mentagrophyte was the commonest isolate obtained (36.3\%) followed by $\mathrm{T}$. rubrum (18.2\%).

\section{References}

1. Smitasarma, Ak Borthakur. A clinicoepidemiological study of dermatophytosis in Northeast India. Indian J Dermatol venereal Leprol 2007;73:427-428.

2. Peerapur BV, Inamdar AC, Pushpa PV, Srikant K. Clinicomycological study of dermatophytosis in Bijapur. Indian $\mathrm{J}$ of Med Microbiol. 2004; 22(4):273-274.

3. Bindu V, Pavithran K. Clinicomycological study of dermatophytosis in Calicut. Indian J Dermatol Venereal Leprol 2002;68:259-261.

4. Kanwar AJ, Mamta, Chander J. Superficial fungal infections In: Valia RG Editor. IADVL Textbook and atlas of dermatology $2^{\text {nd }}$ ed, Mumbai: Bhalani Publishing House; 2001. p215-258.

5. Nelson MM, Martin AG, Heffernan MP. Superficial fungal infection In: Freedberg IM, Eisen AZ, Wolff K, Austen FK, Gold smith LA, Katz SI Editors. Fitzpatrick's Dermatologyin general medicine $6^{\text {th }}$ ed. New York: Mc Graw-Hill Medical Publishing Division; 2003. p1989-2005.

6. Venkatesan G, Ranjit Singh AJ, Murugesan AG, Janaki C, Gokul Shankar S. Trichophyton rubrum- the predominant etiological agent in human dermatophytosis in Chennai, India. Afr J Microbiol Res 2007;9-12.
7. Chinelli, Vianna PA, Sofiatti A, Alexandre, Nunes, Spina $\mathrm{R}$ et al. Dermatophyte agents in the city of Sao Paulo from 1992 to 2002.Rev Inst Med Trop Sao Paulo 2003;45(5):259-263.

8. S Balamuruganvelu, Sreenivasalu V Reddy, Geethavani Babu. Age and Gender wise Seasonal Distribution of Dermatophytosis in a Tertiary Care Hospital, Puducherry, India. Journal of Clinical and Diagnostic Research. 2019; 13(2): 6-10.

9. Mishra N, Rastogi MK, Gahalaut P, Yadav S, Srivastava N, Aggarwal A. Clinicomycological study of dermatophytosis in children: Presenting at a tertiary care center. Indian J Paediatr Dermatol 2018;19:326-30.

10. Pathania S, Rudramurthy SM, Narang T, Saikia UN, Dogra S. A prospective study of the epidemiological and clinical patterns of recurrent dermatophytosis at a tertiary care hospital in India. Indian J Dermatol Venereol Leprol 2018;84:67884.

11. Mahajan S, Tilak R, Kaushal SK, Mishra RN, Pandey SS. Clinico-mycological study of dermatophytic infections and their sensitivity to antifungal drugs in a tertiary care center. Indian J Dermatol Venereol Leprol 2017;83:436-40.

12. Venkatesh V N, Swapna Kotian. Dermatophytosis: A Clinico-mycological profile from a tertiary care Hospital. Journal of International Medicine and Dentistry 2016; 3(2): 96-102.

13. Rao BR, Annapurna E. Dermatophytosis in Visakhapatnam. Indian $\mathbf{J}$ Dermatol Venereol 1973;39(5):209-212.

14. Siddappa K, Mahipal OA. Dermatophytosis in Davangere. Indian $\mathrm{J}$ Dermatol Venereol Leprol 1982;48(5):254-259.

15. Bindu V, Pavithran K. Clinicomycological study of dermatophytosis in 
Calicut. Indian J dermatol Venereol Leprol 2002;68:259-261.

16. Kaviarasan PK, Jaisankar TJ, Thappa DM, Sujatha S. Clinical variations in dermatophytosis in HIV infected patients. Indian J Dermatol Venereol Leprol 2002;68:213-216.

17. Singh S, Beena PM. Profile of dermatophyte infections in Baroda. Indian J Dermatol Venereol Leprol 2003;69(4):281-283.

18. Poyyamozhi JS, Lakshmanan A. Profile of dermatophyte infections among rural population: a facility based prospective observational study. Int J Community Med Public Health 2018;5:1354-9.

19. K. Sri Sandhya, Ritu Vaish, Kandi Venkata Ramana, G. Sandhya. Epidemiological and Clinico-Mycological Profile of Dermatophytosis in a Tertiary Care Hospital, Karimnagar. J Cont Med A Dent 2018; 6(3): 23-27.

20. Janardhan B, Vani G. Clinico mycological study of dermatophytosis. Int J Res Med Sci 2017;5:31-9.

21. Vishalakshi S Pandit, Hita Mehta. A hospital-based cross-sectional clinicomycological study of dermatophytosis in a tertiary care centre. Journal of Pakistan Association of Dermatologists. 2017; 27(4): 375-380.

22. Ramaraj V, Vijayaraman RS, Rangarajan S, Kindo AJ. Incidence and prevalence of dermatophytosis in and around Chennai, Tamilnadu, India. Int $\mathbf{J}$ Res Med Sci 2016;4:695-700.

23. Lavanya V, S.S Solabannavar. Clinicomycological study of Dermatophytosis in a tertiary care centre in Bagalkot. International Journal of Medical and Health Research 2015; 1(2): 63-66.
24. Najotra DK, Choudhary V, Sahni B, Choudhary A. Clinico-epidemiological profile of dermatophytosis in district Samba: a cross sectional study from the state of Jammu and Kashmir, India. Medical Science. 2015; 3(1):183-9.

25. Belukar DD, Barmai RN, Karthikeyan S, Vadhavkar RS. A Mycological study of Dermatophytosis in Thane. Bombay Hospital Journal 2004; 46:2.

26. Guruprasad KY, Javed MW, Roopa C, Ansari H, Takalkar AA. Clinicoepidemiological study of dermatophytosis in teaching hospital of North Karnataka. Int J Res Dermatol 2019;5:106-9.

27. Kumar U, Chauhan MPS, Varma K, A clinico epidemiological study of dermatophytosis in a tertiary care center, Ujjain. Indian $\mathbf{J}$ Clin Exp Dermatol 2019;5(1):89-92.

28. Gupta S.K, Prasad J, Brahmane R. B. Clinico-mycological study of Dermatophytosis at a tertiary medical center of Uttar Pradesh. Trop J Path Micro 2017;3(3):283-288. 